\title{
CAUSES AND TREATMENT OF CONGENITAL ECCENTRIC NYSTAGMUS*
}

BY

\author{
J. RINGLAND ANDERSON \\ Melbourne, Australia
}

THE cause of congenital nystagmus has been considered to be as obscure as the disorder is resistant to treatment. This paper contains little hint of value regarding the former but it is believed that it does contain some for the latter.

Nystagmus may be divided into the following groups :
(1) Visual or fixation nystagmus.
(2) Oculomotor or gaze nystagmus.
(3) Vestibular nystagmus.

The movements of the first are oscillatory, and may be replaced by rhythmic jerks when the eyes are rotated to right or left. The movements of the second group are mainly rhythmic with a fast component in the direction of gaze. They are gaze-determined. The movements of the third group are also rhythmic, but the fast component may be towards one side regardless of the direction of gaze. The nystagmus is side-determined, either towards or away from the affected labyrinth or its connections; the movements are horizontal and rotatory combined, whereas those of the second group are purely horizontal except for a slight rotatory movement at times of the adducted eye.

\section{Congenital Nystagmus}

By " congenital " nystagmus is meant the type that owes its origin to a genetic, intra-uterine, or birth influence. It may not reveal itself until 3 or 4 months after birth, and may await the demands of fixation, or, later, those of conjugate deviation.

Characteristics.-In attempting to study the ocular movements in congenital nystagmus we should exclude first of all the irregular " searching" movements of the blind. We classify those of true nystagmus, as a rule, according to their nature when the eyes are directed in front. It might be wiser to classify them according to their nature in the position of relative rest-the neutral zone. Frequently in the rhythmic type the movements disappear there, and only show their characteristic jerk on deviation from this point. This could be called " rhythmic nystagmuson rotation only".

* Received for publication December 2, 1952. 


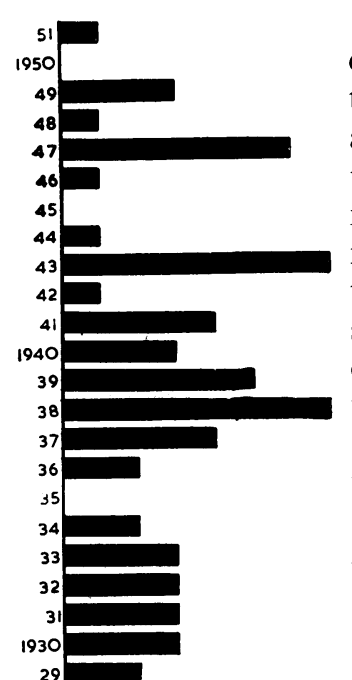

The oscillatory type is usually associated with very defective vision. This is not necessarily so. One case in this series had visual acuity 6/6. When the movements are oscillatory in the position of rest they usually show a rhythmic element on conjugate deviation. Sometimes, even in the position of rest, an occasional jerk due to an oculomotor influence is added with its fast component towards the side of most marked nystagmus. It is difficult to under. stand the not uncommon circular movements. In them, the centre of the cornea moves in a circle around the saggital axis while the 12 o'clock point on the limbus retains its normal position. Lack of balance in tone of the vertical rotators as well as of the horizontal rotators is a likely explanation. At times we also see a slow rotation of the 12 o'clock point - either clock-wise or anti-clockwise. These rotations may occur alone or combined with irregular movements.

It is an advantage when the position of rest coincides with the normal position of frontal gaze. When it is displaced to one side, the patient tends to hold his head to the opposite side so that the position of rest is brought more or less central. This posture of the head could be called the position of election. It is towards the side of greatest nystagmus.

\section{Incidence of Nystagmus: An Apparent Increase}

Over 34,000 patients have been seen in just over 30 years of private practice. Amongst these were 138 with nystagmus, at least 106 cases being congenital (Fig. $1 a$ and $b$ ) with an early and inexplicable onset.

If we plot these congenital cases, omitting several due to rubella, according to their year of birth, we obtain the graph illustrated in Fig. 1( $a)$ and $(b)$. There is an apparent increase. Is this apparent or real? It is possible that many patients with nystagmus, realizing there is no treatment, have ceased when adult to attend a private practice, which would mean the attendance of fewer old patients. During the first few years of practice of course the numbers of patients seen were small, and one naturally sees more patients as years go by, but it is doubtful whether this is an adequate explanation.

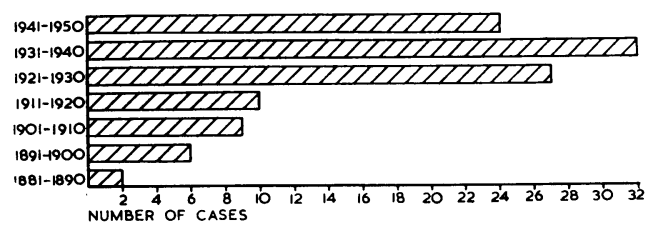

FIG. 1 (b).-Cases listed in Fig. 1 (a) arranged in 10-year periods.

FIG. $1(a)$.- Years of birth of patients with congenital nystagmus examined in private practice between 1922 and 1952 . 
My absence from practice in 1942 may account in part for the scarcity of patients plotted in this year. This can be only a partial explanation, because most patients are not brought for examination until they are over one year of age. The average age at first attendance in twenty recent cases was 21 months. Occasionally the nystagmus is not recognized until the child is older; for example, one who was 7 years old. In these cases the need for conjugate deviation appears to be largely obviated by head rotation, and so the nystagmus is obscured until tested.

Possible Influence of 1939-45 War.-This series is only small and therefore one must be careful when drawing conclusions. Is it possible that the upset at the beginning of the recent war may have had some effect in causing the apparent increase in congenital nystagmus during 1937-43?

As no instances of maternal rubella are included, the relationship with the war is not similar to that of the numerous congenital defects which followed an epidemic of this infection. During this period there were unusual opportunities for the insidious spread of an infectious disease-hitherto regarded as unimportantthrough women at the child-bearing period, for their men-folk were concentrated in military camps. The epidemic came when the population had been free from this disease for a long time, and immunity was low, but rubella was not responsible for the apparent increase of nystagmus in this series. The medical men remaining in civilian practice at that time were grossly overworked, and some of the most experienced obstetricians were on active service; these factors may have led to inadequate pre-natal observation and imperfect technique. The increase however appears greatest between 1937 and 1943. The earlier increase, in 1921-1933, may have been due to the introduction of various forms of twilight sleep. Several mothers in this series stated that they were the first patients to be treated in this way by their doctor.

\section{Present Series of Cases of Congenital Nystagmus}

The 87 patients in this series have been divided into five groups:

\section{Familial Group (12).}

(a) Bilateral visual defects, that is, $\mathrm{R}$ and $\mathrm{L}, 6 / 18$ at most

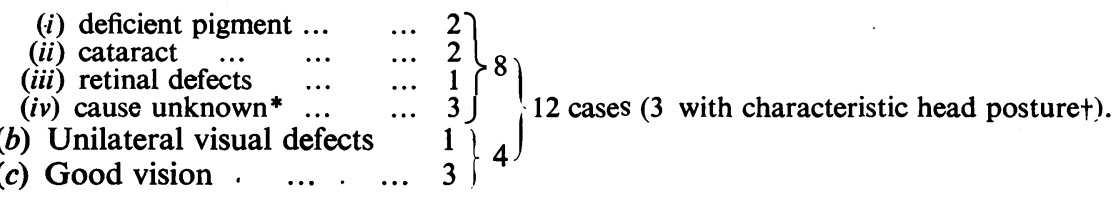

II. Bilateral Visual Defects (31). $-\mathrm{R}$ and L., 6/18 at most.
(a) Albino

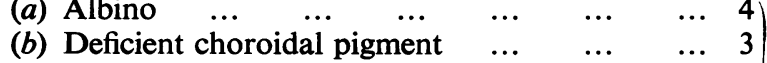
(c) Scattered pigment, macular dots, etc. ... $\quad \ldots \quad 331$ cases $(8$ with characteristic

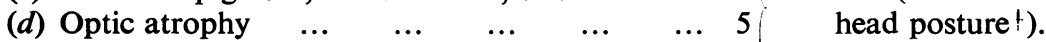

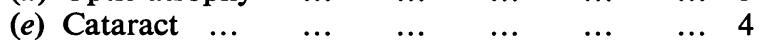

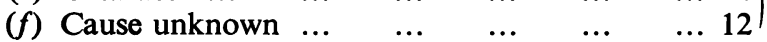

"Unfortunately the remark "cause unknown" does not mean the absence of a fundus lesion. Some of the children were very young and not examined with sufficient thoroughness.

+ Not all were old enough to have developed a head posture. Others were not tested for this feature. 
III. Unilateral Visual Defects. (17). - Left-sided in 13 cases
(a) Optic atrophy
(b) Retinal defects
(c) Cataract ...
$\ldots \quad \ldots \quad \ldots \quad 5$
18 cases ( 10 with characteristic

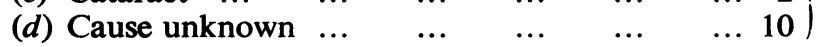 head posture*).
IV. Good Vision (19).
(a) With convergent strabismus
(b) With esophoria ... ...
(c) Without convergence defect
(d) Uncertain ...

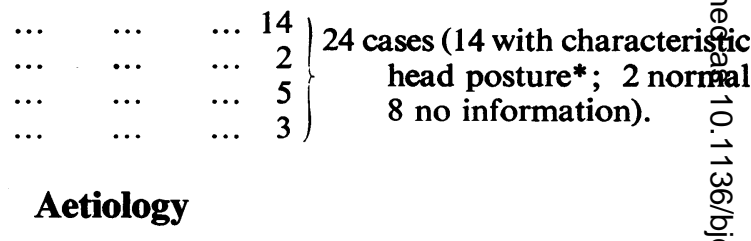

(1) Inheritance.-There were thirteen instances in which the congenifal nystagmus was inherited. In two heredity was blamed simply because thle patients were twins, and in two others because they were brother and sisters. No definite instance of direct inheritance was found. Associated inherited defects included:

(i) The patient's father and sister had ptosis, but only the patient had nystagmus

(ii) Many patients had convergent strabismus which could have been hereditary.

(iii) A variety of transmissible ocular diseases was found, including albinism.

(2) Maternal IIl-Health and Labour.-The mechanism underlying conjugate deviation is young phylogenetically. It is therefore vulnerable during the later stages of pregnancy.

Morbidity due to maternal ill-health, prematurity, natal anoxaemia, a⿳⺈ injury as the most probable main causes of the type of nystagmus we afe considering is shown in the Table (pp. 271 and 272). The main findings wioh respect to parity, trauma and sex are set out below:

\begin{tabular}{|c|c|c|c|c|c|c|c|c|}
\hline $\begin{array}{l}\text { Position } \\
\text { in } \\
\text { Family }\end{array}$ & $\begin{array}{l}\text { First and only.child ... } \\
\text { First of two ... } \ldots \\
\text { Second of two } \\
\text { First of more than two } \\
\text { Second of more than two } \\
\text { Third child or later ... } \\
\text { First of an unknown numb } \\
\text { Uncertain } \ldots\end{array}$ & $\begin{array}{l}\ldots \\
\ldots \\
\ldots \\
\ldots \\
\ldots \\
\ldots \\
\ldots \\
\ldots\end{array}$ & $\begin{array}{l}\ldots \\
\ldots \\
\ldots \\
\ldots \\
\ldots \\
\ldots \text { hildren } \\
\ldots\end{array}$ & $\begin{array}{l}\ldots \\
\ldots \\
\ldots \\
\ldots \\
\ldots \\
\ldots \\
\ldots\end{array}$ & $\begin{array}{l}\ldots \\
\ldots \\
\ldots \\
\ldots \\
\ldots \\
\ldots \\
\ldots\end{array}$ & $\begin{array}{l}\ldots \\
\ldots \\
\ldots \\
\ldots \\
\ldots \\
\ldots \\
\ldots \\
\ldots\end{array}$ & $\left.\begin{array}{r}9 \\
12 \\
6 \\
12 \\
10 \\
8 \\
4 \\
9\end{array}\right\}$ & 70 \\
\hline $\begin{array}{c}\text { Incidence } \\
\text { of } \\
\text { Trauma }\end{array}$ & $\begin{array}{l}\text { Maternal ill-health ... } \\
\text { “Normal " delivery ... } \\
\text { Premature birth } \\
\text { Delayed or difficult labour } \\
\text { Baby burned during first da } \\
\text { Blood incompatibility } \dagger \\
\text { Caesarean because mother's } \\
\text { Uncertain } \quad . .\end{array}$ & $\begin{array}{l}\ldots \\
\cdots \\
\cdots \\
\ldots \\
\ldots \\
\ldots \\
\ldots\end{array}$ & $\begin{array}{l}\ldots \\
\ldots \\
\ldots \\
\ldots \\
\ldots \\
\ldots \\
\text { ious bat } \\
\ldots\end{array}$ & $\begin{array}{l}\ldots \\
\cdots \\
\cdots \\
\cdots \\
\cdots \\
\ldots \\
\ldots \\
\cdots\end{array}$ & $\begin{array}{l}\cdots \\
\cdots \\
\cdots \\
\cdots \\
\cdots \\
\cdots\end{array}$ & $\begin{array}{l}\cdots \\
\cdots \\
\cdots \\
\cdots \\
\cdots \\
\cdots \\
\cdots\end{array}$ & $\left.\begin{array}{r}6 \\
16 \\
2 \\
30 \\
1 \\
2 \\
1 \\
12\end{array}\right\}$ & 70 \\
\hline Sex $\neq$ & $\begin{array}{l}\text { Male ... } \\
\text { Female }\end{array}$ & $\begin{array}{l}\cdots \\
\cdots\end{array}$ & $\begin{array}{l}\cdots \\
\cdots\end{array}$ & $\cdots$ & $\cdots$ & $\begin{array}{l}\cdots \\
\cdots\end{array}$ & $\begin{array}{l}50 \\
33\end{array}$ & 83 \\
\hline
\end{tabular}

* Not all were old enough to have developed a head posture. Others were not tested for this feature. $\uparrow$ The blood group was known of only very few patients in the series.

In a series of 1,470 patients with convergent and divergent strabismus there were 862 females and 598 males is approximately 4.4 to 3 . 
TABLE

MATERNAL HEALTH AND OBSTETRICAL PARTICULARS OF PATIENTS LISTED IN FIG. $1(a)$

\begin{tabular}{|c|c|c|c|}
\hline Case No. & Year of Birth & Parity & Observations \\
\hline & 1951 & Second of two & $\begin{array}{l}\text { Not difficult, but baby badly burned during } \\
\text { first half hour after birth }\end{array}$ \\
\hline 2 & 1949 & Only labour & $\begin{array}{l}\text { Very bad; patient one of twins, weighed } \\
3 \frac{1}{2} \mathrm{lb} \text {; other twin died }\end{array}$ \\
\hline
\end{tabular}

Third of three

1948

1948

1947

5

Only labour

First of two

Only children.

1947
1947

1947

1947

1946

1944

1943

1943

1943

1943

1943

1943

1943

1942

1941

1941

1941

1940

First of three

Only labour

Second of two

First of two

First of two

Second of three

Only labour

First of two

Third of three

First of two

First of three

First of two

First of three

Second of three

1940 or 41

1940

1939

1939

1939

1938 or 39

1938

1938

1938

1938
First of two

No information

First of three

First of three

First of two

Only labour

First of four

Second of two

No information

First of three
Twins

Second of two
Normal

One month premature; mother's health bad for first half of pregnancy

Normal instrumental delivery; baby jaundiced 8 hours after birth, probably because of blood incompatibility. Baby A (2) Rh negative: Mother 0 (4) $\mathrm{Rh}$ negative.

Normal; probably recessive inheritance

Normal; probably recessive inheritance

Normal

Normal

Difficult labour due to contracted pelvis; second stage long, but baby in good state

Face presentation; labour lasted 2 days

Very long but normal; no instruments; eyelids very puffy

Difficult; baby's forehead very bruised

Difficult; deep forcep marks near ears and in forehead

Normal; Glycosuria in 7th month

Very long first stage-very little liquor; baby very distressed; spastic

Arm presentation; scars near left eye

Caesarean delivery because previous baby died 2 days after birth, ? cerebral haemorrhage. Patient slow in speaking, etc; male cousin and grand-uncle with nystagmus

One miscarriage before each child; very slow labour, 3 days and nights; patient's head badly marked

Very long; instrumental delivery after $2 \frac{1}{2}$ days labour

Normal

Breach presentation; not diagnosed for 2 days; baby black- "miracle it lived" (2nd parity was miscarriage)

One month premature; first child had lived only a few hours

Quick labour

Forceps; injured; scars on head beside left eye; left cataract

Normal; inherited syphilis

Mother very seasick during second and third month; rapid birth

Normal

Patient second of twin boys; normal; inherited from father's parents who were cousins

Normal though instrumental; depressed and vomiting

Very difficult; mother's blood group A (Moss 11) $R h$ negative, Father's 0 (Moss IV) $R h$ positive 
TABLE-continued

MATERNAL HEALTH AND OBSTETRICAL PARTICULARS OF PATIENTS LISTED IN FIG. 1(a).

\begin{tabular}{|c|c|c|}
\hline Case No. & Year of Birth & Parity \\
\hline 34 & 1938 & Only child \\
\hline 35 & 1938 & First of five \\
\hline 36 & 1938 & Last of five \\
\hline $\begin{array}{l}37 \\
38 \\
39\end{array}$ & $\begin{array}{l}1937 \\
1937 \\
1937\end{array}$ & $\begin{array}{l}\text { No notes } \\
\text { Second of three } \\
\text { First of three }\end{array}$ \\
\hline $\begin{array}{l}40 \\
41\end{array}$ & $\begin{array}{l}1937 \\
1937\end{array}$ & $\begin{array}{l}\text { No notes } \\
\text { First of two }\end{array}$ \\
\hline 42 & 1936 & $\begin{array}{l}\text { First (followed } \\
6 \text { miscarriages) }\end{array}$ \\
\hline 43 & 1935 & Second of three \\
\hline
\end{tabular}

Second of three

No notes

No notes

1933 * First of four

Last of four

First of three

Only child

First of two

First of four

$\begin{array}{ll}53 & 1930 \\ 54 & 1930 \\ 55 & 1929 \\ 56 & 1929 \\ 57 & 1927 \\ 58 & 1927 \\ 59 & 1926 \\ 60 & 1926 \\ 61 & 1925 \\ 62 & 1925 \\ 63 & 1925 \\ 64 & 1923 \\ 65 & 1923\end{array}$

Third of three

Second of three

Second of two

Second of three

Third of three

Fourth of four

First child of three

Fourth of seven

First of two

Second of three

Only child

Second of three

First of two

Bad; instrument marks on both sides of both eyes, especially on outer sides

Twilight sleep; forceps; right eye injured 峛nd was bandaged

First and second stillborn, third miscarriage, fourth died when 2 years old. Fiffth (patient) birth instrumental, difficult to rear

Normal

Weighed $10 \mathrm{lb}$., narrow pelvis. Obstetriclan wrote: "I was too strenuous in use of narcotics to induce 'twilight sleep', and had to resort to 'blowing up' the lungs as a means of artificial respiration."

Normal; nystagmus and strabismus not notised till after whooping cough, at age 5??

$\mathrm{Rh}$ positive; at 6 months albuminuria and tachycardia, normal labour

One of first " twilight sleep" deliveries; ;eye caught on pelvis bone", head injumed, maternal grandfather and male cousin nystagmus

Very slow; but no instruments

Induced at $8 \frac{1}{2}$ months, because baby thought to be stillborn

Normal; no instruments; preliminary twi sleep

Normal

Very slow-53 hours; faulty position

Normal

Weighed $10 \frac{1}{2} \mathrm{lb}$.- -very difficult. The 要ird (previous) baby had been "carried "Ofor 11 mths; a Caesarean was performed but baby died

Normal

Normal

Normal

Normal

Very difficult; baby nearly died

Did"not breathe for some time; brother Gुnd uncle affected

Very difficult; skin removed from ears 古 face; 3 weeks overdue

Weight $10 \mathrm{lb}$; ; one of first twilight sleep; head injured; eye caught on pelvis bone

Very difficult; contracted pelvis

Difficult; version; scar on head

Difficult; brain injured 
A study of these reports leads to the following conclusions:

1. Maternal health probably played only a small part as a cause. Most mothers stated that their health was good. It is possible that mild virus infections can occur that, though apparently negligible, may affect a developing foetal tissue. Even though many of the children were born during the " rubella period", none of these mothers had this disease during pregnancy. A subclinical attack could not explain more than one or two. Three children with " rubella " cataract and nystagmoid movements were omitted.

2. Prematurity plays an unimportant part as a cause of nystagmus. Only two of the births were premature, and then only by one month.

3. Anoxaemia may have been very important. Many of the labours were delayed. Anaesthetists consider that cerebral tissue will be damaged after several minutes without breathing even if artificial respiration is successful. It makes one ask whether there is a time-limit, which if exceeded, makes attempts at artificial respiration valueless for, even if successful, is not the certainty of serious permanent disability such that merely being alive is not worth while? Various forms of "twilight sleep" are under suspicion.

4. Cerebral injury was probably the cause of nystagmus in some patients. Many of the labours were difficult, and some reports suggest that delayed recognition of and imperfect treatment of faulty presentations were responsible.

How are we to explain the cases that arise with perfect maternal health and normal labour? The families are often too small for us to exclude recessive inheritance. The effects of anoxaemia and of local trauma are possible causes in some of those instances of normal birth without a detailed medical report. But as Dr. Kate Campbell of Melbourne states:

In studying congenital defects we must go beyond the actual birth and maternal illness to the nature of the particular placenta, and then even beyond the "Mrs." to the "Miss".

The attitude towards human pregnancy should resemble more closely that found on a first-class stud farm!

In England in the last 50 years there has been a great decline in infant mortality after the first week of life, but there has been little change during the first week. Difficult births and birth injuries may be a partial explanation of this finding. Whatever the cause, how much is preventable?

The evidence indicates that the present neonatal mortality and stillbirth rates could be reduced by one-third to one-half; if that were so about 15,000 babies would be saved each year in England and Wales alone.

Analgesics and hypnotics ... often prolong the duration of labour and may increase the need for operative delivery, with consequent danger of birth injury and intranatal asphyxia. Probably 60 to 70 per cent. of neonatal deaths are due to conditions related in one way or another to birth. Birth injury is one of the leading causes of death in the first month, and the majority of such deaths occur in the first week. It is the immediate cause in approximately one-fourth to one-third, of neonatal mortalities . . . Two important predisposing causes are prematurity and anoxaemia (asphyxia). The latter condition . . . . is considered to play a part, often a leading part, in about 50 per cent. of neonatal deaths ... . About half the neonatal deaths are said to be due to prematurity from one cause or another, and the added handicap of possible morbidity in the survivors should not be forgotten (Neonatal Mortality and Morbidity, 1949). 
The dictum of Sage (1944) cannot be repeated too often :

The ultimate evaluation of any method of analgesia will depend on the price paid for the mother's comfort in terms of infant mortality.

We must consider morbidity due to natal anoxaemia and injury as the most probable main cause of the type of nystagmus now under consideration. The characteristics of this condition may be summarized as follows:

1. The ocular movements are usually pendular or oscillatory, but may be rhythmic. They are mainly horizontal, and become coarser on conjugate deviation The fast component is in the direction of gaze and is usually more marked to one side than to the other.

2. These movements become much reduced or absent in a position of rest, which is frequently eccentric.

3. When the position of rest is eccentric, a posture of the head will be chosen that tends to "centre" this displaced position of ocular rest. The head is turned in the direction of greatest nystagmus. As a rule the favourite posture of the head is one of rotation to one or other side with a slight displacement of the chin up or down. At times there is a tilt towards one shoulder. Sometimes a weakness of one particular muscle is superimposed on the nystagmus and influences the choice of ocular and head position. In some patients the rotation of the head that permits clearest vision is so marked that it seems greater than is necessary to bring the position of ocular rest to the frontal site (Fig. 2). A braking influence on the nystagmus by tonic neck reflexes is suggested by the extreme rotation of the eyes.

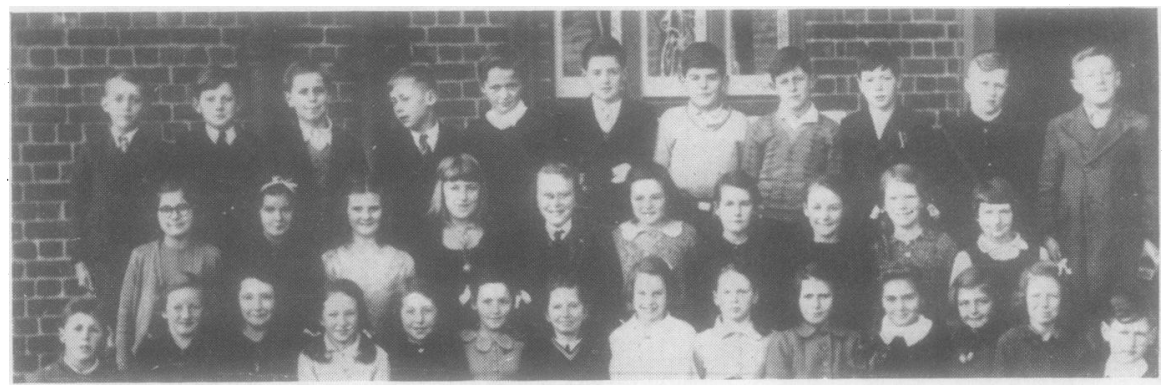

FIG. 2.-Fourth from the left, in the back row, is one of the patients operated on. He shows the characteristic head posture as he tries to see more clearly.

4. The vision may be good, for example $6 / 6$; it is usually greatest in the direction of ocular rest and with the head in the posture of choice.

5. The nystagmus may be associated with other ocular defects that reduce vision, such as cataract, retinal lesions, etc; strabismus is frequent.

6. Unless mentally defective, the children do well at school.

7. The parents and other relatives are unaffected, except for a small group in which the condition is inherited and then recessively.

8. The mothers' health during pregnancy was almost always good, but the labour was usually difficult, and this is apparently the most important factor.

9. Males are more frequently affected than females.

Site and Nature of Lesion

The two main ocular defects of patients included in this study are nystagmus, usually gaze-determined, and a position of ocular rest that may 
be eccentric and lead to a characteristic head posture.

Now what could cause these two typical ocular defects? The physiological pesition of rest is the result, not of a complete lack of muscle tonus, "but of a minimal and balanced tonus of all the muscles acting together" (DukeElder, 1932). The balance depends on the equality of the impulses from the two halves of the central nervous system, the two labyrinths, and the retinae. What can produce the displacement of the position of rest to one side? Is it likely to be a cortical or a subcortical lesion? Could a lack of development of or an injury to the cortical centres controlling conjugate deviation to one or other side, unbalance the ocular muscle-tone, and alter the position of rest? Equilibrium would then be obtained to one or other side. The head would be rotated to the opposite side if the eyes were to be at rest when confronting the object exciting interest. Would such a lesion also explain the nystagmus? The form of nystagmus here considered is due to failure to maintain a new position of the eyes taken up in response to volition. It is not due so much to failure to deviate conjugately as to failure to retain the deviation. As a rule full deviation can be obtained by encouragement. The agonists respond to volition, but instead of the antagonists remaining relaxed as they normally do, they contract so that the eyes return to the first position, only to be moved away again as the impulse of volition takes charge again. There is a failure of the coordination that establishes equilibrium of the eyes in motion. The distribution of tone to the muscles in contraction and relaxation is not balanced. Is the defect in this "centre" one that permits an inadequate contraction or a too-brief relaxation? Or is it, through faulty development, a form of primitive stretch reflex? Is it comparable with an intention tremor? We do not know.

The movements are usually spontaneous but become more marked when an object is being followed, and when the eyes attempt to rotate in response to volition. Vestibular responses have also been found to be abnormal, and those that normally followed opticokinetic stimulation may be absent on rotation of the drum to one or both sides. It is unlikely that several lesions are present to explain these separate manifestations. Such would be necessary to account for interference with the 2nd frontal and the occipital gyri and their inter-communications as well as their several descending ocular motor pathways; moreover, upper lesions are inclined to produce conjugate deviations and not nystagmus. It is more reasonable to expect a lesion of a centre in the pons or midbrain to which these pathways run, which could also account for the displaced position of rest.

The exact structural basis for the control of conjugate deviations is not known. The main centre may be within the vestibular nuclei, since their " destruction abolishes all lateral (not vertical) conjugate movements from stimulation of the frontal and occipital cortex " Cogan (1948). It is known also that the lateral lobes of the cerebellum are concerned with motor coordination and that their stimulation leads to conjugate deviation. It is 
conceivable that trauma to a collection of cells within or close to the vestibular nuclei, or delayed medullation of their connections, may be the lesion responsible for congenital nystagmus.

This explanation is supported by the fact that known lesions can produce a similar type of nystagmus, acquired in later life. This has been called "asymmetric gaze nystagmus" and its presence suggests a focus within the pons. This form however, like other acquired forms, appears not to have a displaced position of rest. Kestenbaum (1946) states that, unlike the symmetrical form which is usually due to disseminated sclerosis, the asymmetrical form suggests the site but not the nature of the lesion.

The vital factor in the development of congenital defects is often the time at which a suitable agent acts. This agent, or possibly one of a variety of agents, acting at this precise time may be effective. The critical time in this form of nystagmus appears to be associated with birth, and a possible agent is a transient anoxaemia. This could be due to a variety of causes such as undue delay, faulty presentation, unwise analgesia, or even an attempt to hasten delivery.

The vulnerable tissues are likely to be those that are immature. A nucleus or an associated centre may contain cells which are undergoing mitotic changes at the time. If their development is delayed they may be left behind in the race of growth which must be orderly if normal maturity is to be attained.

Structures that are immature at birth are those that pertain to functions that are relatively youthful phylogenetically. Such are the movements of conjugate deviation of the eyes, and ocular convergence. These movements are rare in all but the higher mammals and they appear relatively late in the individual. For example, conjugate deviation is very unsteady until 5 or 6 months of age, and convergence is often not observed until the age of 5 months. The oculomotor nuclei and the association tracts, such as the dorsal longitudional bundle, that might be connected with this form of nystagmus show a marked degree of histological maturity in the early embryo. The absence of conjugate deviation for some weeks after birth however, suggests that the pattern of the mechanism concerned is not consolidated until about then. Oedema or a minute haemorrhage or some effect of anoxaemia might affect this mechanism at this precise time. The damage is done and the full development of the cells or fibres is delayed or prevented. The development of functions dependent on tissues not in a vulnerable stage may proceed normally when the dystrophic influence has ceased.

It is suggested that in this form of nystagmus a portion of the mechanism concerned with conjugate deviation is affected. This may not develop fully, and neither may other structures that are vulnerable at the same time. This may account for the association of strabismus, and anomalies of the retina and choroid with nystagmus. Of course damage to the retina may be due to indirect trauma during labour rather than to asphyxia. 


\section{Spontaneous Cure}

It must be remembered that in many patients nystagmus grows less during the first few years of life. In one child in the present series the nystagmus completely disappeared.

Case 23 (see Table), Female infant, brought to see me at the age of 11 months because of "eye movements", had gaze nystagmus, coarser and more marked to the left and finer to the right. She was examined on five occasions, and at the last glasses were ordered, after atropine. Right and Left $+2.0 \mathrm{D}$. cyl., $90^{\circ}$. The child was not seen for 10 years, and her mother then stated that the movements had disappeared 6 months after wearing the glasses.

Vision in the right eye was then $6 / 6$ partly with $+0.5 \mathrm{D}$. cyl. at $90^{\circ}$.

Vision in the left eye was $6 / 5$, with $+0.5 \mathrm{D}$. cyl. at $90^{\circ}$.

The fundi and media were normal. It is suggested that if all children with nystagmus were carefully followed more instances of reduction and disappearance would be observed.

This makes one ask whether the ill-effects of birth clear away, or whether the controlling centre can be delayed in development and mature later, so that in the early years of life nystagmus may lessen or disappear.

The differentiation of the macula lutea and the medullation of the optic nerve fibres are not completed until about the fourth month of life. Accurate fixation is not possible until then. It is likely that the appearance of nystagmus is rare until accurate fixation excites the necessary muscle tone, but on this question, further information is required.

\section{Treatment}

We must combat the tendency to consider that there is no treatment for children with nystagmus.

The first essential is to make sure that no undue strain exists in the home or school. The child requires more rest, and reacts more to haste and tension than do most children. His hours of rest should be adequate and spaced. The teacher should be warned that a "go-slow" policy will give the best results, but that the child should not be neglected. So often these children appear to be compensated by a special gift that many normal sighted children do not have. It is wise to encourage the parents. Very often a devoted mother puts all her available time at such a child's disposal. One must remember that nystagmus usually lessens during the first decade and occasionally disappears. Parents should be warned that some children read more easily if the book is held at an unusual angle and that this should not be discouraged. The habits adopted by children with nystagmus to aid their ability to read are very varied, and in my experience children with nystagmus make good progress at ordinary schools and later find satisfactory ways of earning a living. This is partly because their reading ability is greater than their distance vision suggests.

One boy stated that he had voluntary control of his " movements". He had had a head tilt until he was 5 years of age, when his mother stated, " the head tilt went and his eyes crossed". He can now clarify his vision of objects by concentrating on them with either eye and his nystagmus is much less than when he just looks with both eyes. At 22 years of age he has his 
own research-workshop in the Post-Master General's department.

Such children could be handicapped greatly by being sent to a Sight-음 Saving School unless its educational facilities were at least as great as those $\vec{F}$ available to normal-sighted children.

If any convergence-excess is present, orthoptics should be tried. The most $\frac{\mathrm{C}}{0}$ valuable treatment is by occlusion. Occlusion appears to lessen the tonus $\frac{\bar{\omega}}{\vec{D}}$ for convergence, which is possibly in excess anyway in these children. Train- $\propto$ ing in relaxation is of value. Full correction of refraction is essential and $\%$ sometimes an over-correction with convex spheres or bifocals may help. $\vec{\circ}$

Case 11, Boy, aged 7 years, had a left convergent strabismus, rhythmic nystagmus, and $\vec{\omega}$ his head posture was to the right-the direction of greatest nystagmus. After occlusion $\stackrel{\circ}{\circ}$ and orthoptic training his nystagmus appeared to be less and he kept his head straighter. $\frac{}{0}$. His resting angle lessened from $+35^{\circ} \frac{\mathrm{L}}{\mathrm{R}} 11$ dioptres to $+17^{\circ} \frac{\mathrm{L}}{\mathrm{R}} 11$ dioptres in six months $\underbrace{\dot{\omega}}_{\text {iv }}$ and his eyes appeared to be straight unless he was tired or excited.

It is wise when testing vision subjectively to do so with the head and eyes in 음 the position of rest. Surprisingly good acuity of vision may be found. Sometimes the examination of the fundi is easier in this position. In other children the movements of the eyes are arrested when converged. This finding $\vec{c}$ explains the reading ease of some patients, and also suggests the easiest of position for the examiner to see fundus details.

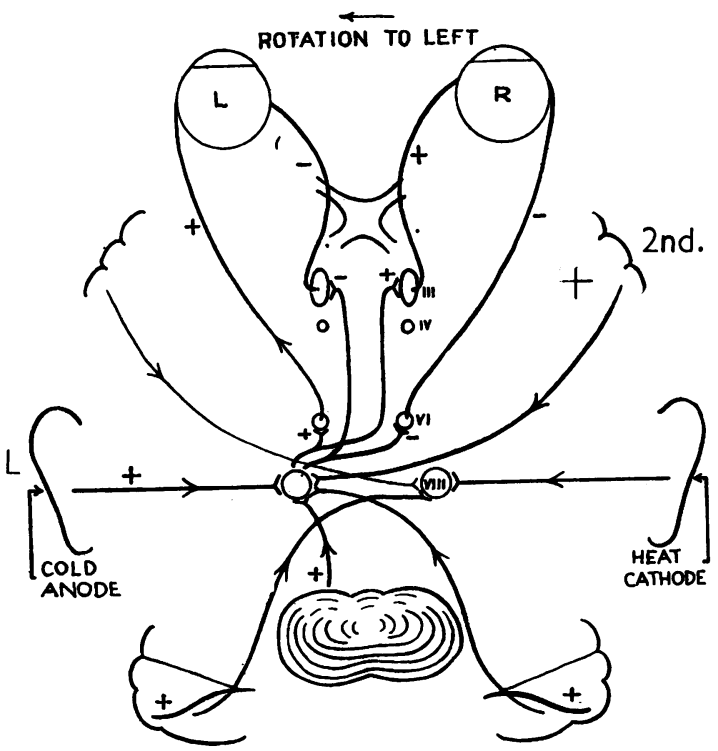

Fig. 3.-Diagram of possible courses of certain main impulses capable of producing conjugate deviation to the left. They proceed from the calcarine fissures, the right second frontal gyrus, the left vestibule, and the left lateral lobe of the cerebellum. Courses are marked + for contraction and - for relaxation.

\section{Surgical Intervention}

As far as I know no operation has been recommended for nys- $\frac{\mathbb{D}}{\square}$ tagmus. It seems reasonable $\stackrel{2}{\vec{F}}$ however to operate at least on $\frac{0}{3}$ those that owing to a displaced position of ocular rest, have an abnormal head posture, since 응. such a posture is a handicap, particularly at school. It may $\underline{3}$. be wise to operate when there is 8 a marked difference in nystagmus to either side.

The stimulus responsible for $D$ this type of nystagmus is probably that which produces the $N$ slow return to the position of $N$ rest (Fig. 3). The fast outward N jerk is volitional. Is the muscle $\frac{\omega}{\sigma}$ tone for this fast movement too weak to maintain the rotation, $\stackrel{\odot}{\Phi}$ or is the stimulus which permits $\stackrel{0}{+}$ the slow returning movement $ᄁ$ too strong? If we consider that the ocular rotators responsible 
for the slow movements are, at least, relatively too strong, or that their tonus is excessive, it seems reasonable to weaken them. This can be done by a bilateral recession operation.

In patients with a displaced position of rest, the tone of the horizontally-acting rectus muscles is not balanced in frontal gaze, as is normal. Instead, the tone of the rotators on the side remote from the position of rest is greater than that of their opponents. If we weaken the latter sufficiently, they will require extra tone when the eyes are in the central position, and this should restore equilibrium, and lessen or remove the nystagmus. The new position of rest will then be in the midline, and the head need not be turned to one side to bring the eyes to their position of rest before the object of fixation (Fig. 4).

It had been observed that nystagmus is not infrequently lessened after an operation for strabismus had been performed. One man, aged 22 years, at the time of operation for a left convergent strabismus of at least 60 dioptres, had been worried by the apparent movement of a wall from side to side. It is unusual for patients with congenital nystagmus to be conscious of movement of objects, and this man was conscious only of the movement of walls. Vision was $6 / 9$ in the right eye and $6 / 12$ in the left. Both nystagmus and strabismus had been life-
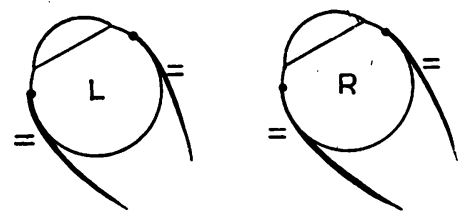

L. Eyes in eccentric position of rest with balanced muscle tone
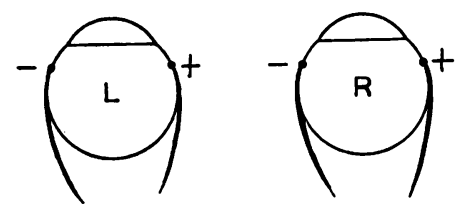

2. Eyes in frontal gaze with tone of right rotators in excess
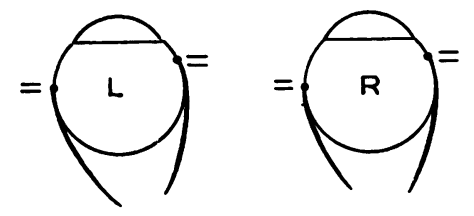

3. Eyes in frontal gaze with restoration of balanced muscle tone after recession of left rotators

FIG. 4.-Eyes in congenital nystagmus with eccentric position of rest.

long. The conscious move-

ment vanished after a recession of each internal rectus muscle and a resection of each external rectus muscle, even though an angle of anomaly of 20 dioptres persisted. This observation and the above line of reasoning encouraged the author to treat the following patients:

(1) Case 12, Female, born 1943, had a coarse horizontal rhythmic nystagmus when looking to the right, but this was much less when looking to the left. Her position of rest appeared to be almost $45^{\circ}$ to the left of the central position. When facing front her uncorrected vision was $6 / 60$, but when she adopted the head posture of choice visual acuity was $6 / 18$, two letters. Her face was then rotated to the right, her head slightly tilted to the right shoulder, and her chin slightly raised.

Operation.-The left external rectus was recessed $6 \mathrm{~mm}$. and the right internal rectus $5 \mathrm{~mm}$. The latter was recessed less than the former because it appeared to be more powerful. There was a convergent strabismus of +6 dioptres before the operation and of +5 one month afterwards. The fusion range was from $-4^{\circ}$ to $+25^{\circ}$ and stereopsis was good. After the operation the nystagmus in frontal gaze was considerably less, and the child's mother considered that there was less turning of the head. Motion films appeared to 
confirm this view. The schoolmaster later wrote to the mother stating that there was no longer any need to stand the child in front of the class to read the blackboard, as she could see it from her position in the room. She had also started to learn the piano.

(2) Case 20, Female, born 1941, had a coarse nystagmus when looking to the right, and much less towards the left. The head was usually turned towards the right, with chin tilted slightly to the left.

Operation.-A $5 \mathrm{~mm}$. recession of the left external rectus and the right internal rectus was planned. (Owing to the enforced absence of the author, Dr. Hugh Ryan carried out this plan for him). Before operation the angle was $0^{\circ}$, and 7 months later it was $+1^{\circ}$. The mother considered that there was little improvement until a new master, who had three children of his own and was more sympathetic towards the patient, took charge of the child's class. This was an important observation, for in my opinion the nystagmus was considerably less in the central position and the head posture was less abnormal.

(3) Case 18, Male born 1943, had nystagmus that was considerably more marked to the right than to the left, and had a tendency to turn his head to the right. The right vision when corrected was $6 / 12$ partly, and the left was $6 / 18$. His angle was $0^{\circ}$, fusion $-5^{\circ}$ to $+22^{\circ}$.

Operation.-After recession of the left external rectus muscle and the right internal rectus muscle his angle was $-1^{\circ}$. His nystagmus appeared to be reduced in frontal gaze, and his mother said that he did not tilt his head.

(4) Case 35, Male, born 1938, had slight nystagmus with little difference between right and left conjugate deviation. His nystagmus disappeared on convergence and became more marked on right occlusion. Vision was $6 / 12$ corrected in the right eye, and 6/60 in the left. Vision improved to $6 / 9$ in the right eye with left conjugate deviation, and lessened to $6 / 60$ when his head was to the left. His head was turned to the right for clear vision.

Operation.-His left external and right internal rectus muscles were recessed. His angle before operation was $-10 \mathrm{~L} / \mathrm{R} 6$, but 2 weeks after operation it was $-9^{\circ}$, and his head posture was improved.

\section{Conclusions}

(A) 1. Most of the patients with nystagmus seen in 30 years of private practice had a congenital form of the condition.

2. There was an apparent increase in its frequency between 1921 and 1933 and between 1937 and 1943.

3. Recessive inheritance was present in seven males and four females.

4. In the majority labour had been delayed or difficult.

5. Congenital nystagmus tends to lessen after the first few years of life.

6. Males are more commonly affected than females. This is in contrast with convergent strabismus which, in the author's series, affected females and males in the proportion of $4.4: 3$.

7. This series has not yet been sub-divided into visual, oculomotor, latent, and possibly other groups. One group however is given special consideration and this could be called congenital eccentric nystagmus.

(B) 1. In these patients the nystagmus is mainly rhythmic, though in most it is oscillatory or pendular in the central position. The movements usually lack symmetry being coarser and slower to one side, and finer and faster to the other. The 
position of rest is eccentric, causing rotation of the head to the opposite side, i.e., the side of greatest nystagmus. The position of choice may be one of full rotation of the head to one side with full ocular rotation to the other side. The ocular rest so obtained may not be attained by mere complete conjugate deviation.

2. The visual acuity of these patients varied from $6 / 6$ to less than $6 / 60$. Visual deficiency in those with poor vision probably prevented the acquisition of normal fixation. Such cases could be classed as examples of fixation or of visual nystagmus. It is doubtful whether it is justifiable to include under this heading, those with practically normal vision unless there is evidence that their acuity was poor during the period when fixation was being acquired. Otherwise these cases are more suitably placed under the heading of gaze or oculo-motor nystagmus. They would have a motor rather than a sensory origin. Thus we should have examples of congenital eccentric nystagmus of either the gaze type or the fixation type.

3. Such patients can be helped by a bilateral recession of the muscles responsible for the slow component of the nystagmus in the direction in which it is greatest.

4. Such an operation should bring the position of rest to the centre and slow down the nystagmus.

5. A convergent strabismus associated with nystagmus can be treated at the same time by at least a recession of the other internal rectus.

\section{REFERENCES}

Cogan, D. G. (1948). "Neurology of the Ocular Muscles", p. 163. Thomas, Springfield, Ill.

Duke-Elder, S. (1932). "Text-book of Ophthalmology", vol. 1, p. 580. Kimpton, London.

Kestenbaum, A. (1946). "Clinical Methods of Neuro-Ophthalmologic Examination ", p. 253. Grüne and Stratton, New York.

NeOnatal Mortality AND MORBIDITY (1949). Report by a Joint Committee of the R.C.O.G., and the B.P.A. Reports on Public Health and Medical Subjects, No. 94. H.M.S.O., London. See also Brit. med. J., 1, 444 and 450.

Sage, E. C. (1944). J. Amer. med. Ass., 124, 339. 